\title{
Design of a Rectangular Microstrip Patch Antenna Using Inset Feed Technique
}

\author{
Devan Bhalla, Krishan Bansal \\ (ECE, Bharati Vidyapeeth's College of Engineering, Delhi, India) \\ (ECE, Bharati Vidyapeeth's College of Engineering, Delhi, India)
}

\begin{abstract}
Today in the world of communication systems the most widely researched area is of wireless technology and a study of communication systems is incomplete without an understanding of the operation of the antennas. In the recent years of development in communication systems a need for the development of lightweight, compact and cost-effective antennas that are capable of maintaining high performance over a wide spectrum of frequencies. This technological trend has focused much effort into the design of a Micro strip patch antenna. In this work, the simulation tool of IE3D is used to study the performance and gain of the rectangular Microstrip patch antenna. The design and simulation of patch antennas is widely used in mobile cellular phones today, and our emphasis in this work is on optimization of a $2.4 \mathrm{GHz}$ rectangular Microstrip patch antenna. The return loss and the various gain plots have been studied along with the radiation patterns.
\end{abstract}

Keywords: Gain, Inset feed, Patch antenna, Radiation pattern, Return Loss.

\section{INTRODUCTION}

An antenna is an electrical conductor or a system of conductors which is "that part of a transmitting or receiving system that is designed to radiate or receive electromagnetic waves"[1]. A Microstrip antenna consists of a thin metallic conductor which is bonded to thin grounded dielectric substrates. The size miniaturization of Microstrip patch antenna is crucial in many of the modern day practical applications, like that of Wireless local area networks(WLAN's), mobile cellular handsets, global position satellites (GPS) and other upcoming wireless terminals. Patch antennas play a very significant role in today's world of wireless communication systems. A Micro strip patch antenna (Fig 1) [3] is relatively simple in construction and makes use of a conventional Micro strip fabrication technique which comprises of the etching of the antenna element pattern in a metal trace which is bonded to an insulating dielectric substrate, such as a printed circuit board(PCB), with a continuous metal layer bonded to the opposite side of the substrate which acts as the ground plane. The most commonly used Micro strip patch antennas are rectangular patch antennas, and even circular patch antennas are widely used.

\section{Microstrip PATCh ANTENNA: DESCRIPTION AND DESIGN PRINCIPLE}

Microstrip patch antennas possess a very high antenna quality factor $(\mathrm{Q})$ which represents the losses associated with the antenna where a large Q would lead to a narrow bandwidth and low efficiency. The factor Q can be reduced by increasing the thickness of the dielectric substrate but as the thickness will increase there will be a simultaneous increase in the fraction of the total power delivered by the source into a surface wave which can be effectively considered as an unwanted power loss since it is ultimately scattered at the dielectric bends and causes degradation of the antenna characteristics. Other problems such as lower gain and lower power handling capacity can be overcome by using an array configuration for the elements which is a collection of homogeneous antennas oriented similarly to get greater directivity and gain in a desired direction. The inset-fed microstrip antenna provides impedance control with a planar feed configuration.

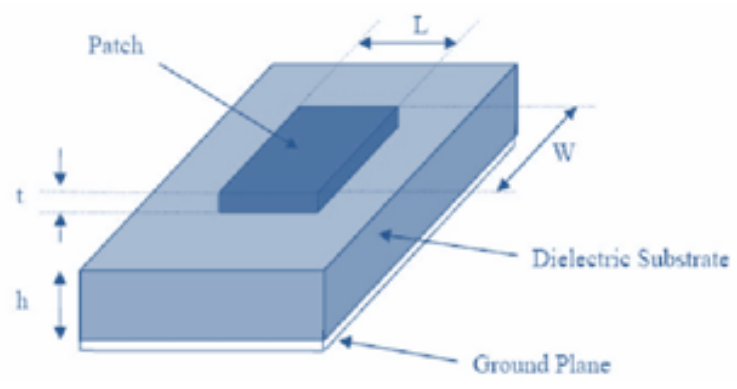

The structure of the Micro strip patch antenna consists of a thin square patch on one side of a dielectric substrate and the other side having a plane to the ground. In its most fundamental form, a Micro strip antenna consists of a 
radiating patch on one side of a dielectric substrate which has a ground plane on other side as shown in the figure below. The patch is generally made of conducting material such as copper or gold. The basic antenna element is a strip conductor of length $\mathrm{L}$ and width $\mathrm{W}$, on a dielectric substrate. The thickness of the patch being $h$ with a height and thickness $t$ is supported by a ground plane. The rectangular patch antenna is designed so that it can operate at the resonance frequency. The length of the patch for a rectangular patch antenna normally would be

$$
0.333 \lambda<\mathrm{L}<0.5 \lambda,
$$

Where, $\lambda$ being the free space wavelength. The thickness of the patch is selected to be in such a way that is $t<<$. The length of the patch can be calculated by the simple calculation from $[3,7]$

$$
\mathrm{L} \approx 0.49 \lambda \mathrm{d}=r \varepsilon \lambda 49.0
$$

The height $h$ of the dielectric substrate is usually

$$
0.003 \lambda_{o} \leq h \leq 0.05 \lambda o \text {. }
$$

The dielectric constant of the substrate ( $\varepsilon r$ ) is typically in the range $2.2 \leq \varepsilon r \leq 12$.

WORKING: The patch of the antenna is being excited by feed which is done by edge feed, a probe feed or coaxial feed or an aperture feed. When the patch is excited by feed a charge distribution is being established between the ground plane and the underneath of the patch. The underneath of the patch is charged to positive and the ground plane is charged to negative after the excitation by feed. The attractive forces are being setup between the planes i.e., patch underneath and the ground plane. The patch antennas radiate in the first case due to the fringing fields between the underneath of the patch and the ground plane. [7,8] For good antenna performance, a thick dielectric substrate having a low dielectric constant is desirable since this provides better efficiency, larger bandwidth and better radiation. However, such a configuration leads to a larger antenna size. In order to design a compact Micro strip patch antenna, substrates with higher dielectric constants must be used which are less efficient and result in narrower bandwidth.

\section{DESIGN SPECIFICATIONS}

IE3D is an integral full-wave electromagnetic simulation and optimization packages for analysis and design of 3D and planner microwave circuits MMIC, RFIC,RFID, antennas ,digital circuits and high speed printed circuit broads(PCB).since its formal introduce in 1993 IEEE international Microwave Symposium(IEEE IMS 1993),IE3D has been adopted as industrial standard in planner and 3D electromagnetic simulation. $[13,16]$ The essential parameters for the design of a rectangular Microstrip Patch Antenna are:

1. Calculation of width (W):

$$
W=\frac{c}{2 f_{0} \sqrt{\frac{\left(\varepsilon_{r}+1\right)}{2}}}
$$

Substituting $c=3 \mathrm{e} 8 \mathrm{~m} / \mathrm{s}, \varepsilon_{r}=3.4$ and $f_{o}=2.4 \mathrm{GHz}$, we get:

$$
W=42.1 \mathrm{~mm}
$$

2. Calculation of effective Dielectric constant $\left(\varepsilon_{\text {reff }}\right)$

$$
\varepsilon_{r e f f}=\frac{\varepsilon_{r^{r}}+1}{2}+\frac{\varepsilon_{r^{r}}-1}{2}\left[1+12 \frac{h}{W}\right]^{\frac{1}{2}}
$$

Substituting $\varepsilon_{r}=3.4, W=42.1 \mathrm{~mm}$ and $h=1.5 \mathrm{~mm}$ we get:

$$
\varepsilon_{\text {reff }}=3.2
$$

3. Calculation extension Length:It is used for calculating resonant frequency of Micostrip antenna.

$$
\Delta L=0.412 \frac{\left(\frac{W}{h}+0.264\right)\left(\varepsilon_{\text {reff }}+0.3\right)}{\left(\varepsilon_{\text {rejf }}-0.258\right)\left(\frac{W}{h}+0.8\right)}
$$


Substituting $\varepsilon_{r e f f}=3.2, W=42.1 \mathrm{~mm}$ and $h=1.5 \mathrm{~mm}$ we get:

$$
\Delta L=0.659 \mathrm{~mm}
$$

4. Calculation of Length (L)

Effective Length ( $\left.\mathrm{L}_{\mathrm{eff}}\right)$ :

$$
L_{e f f}=\frac{c}{2 f_{o} \sqrt{\varepsilon_{r e f f}}} \quad \text { and } \quad L=L_{e f f}-2 \Delta L
$$

Substituting $L_{e f f}=34 \mathrm{~mm}$ and $\Delta L=0.7 \mathrm{~mm}$ we get:

$L=32.56 \mathrm{~mm}$

The parameters for the patch in IE3D simulation tool are the following:

- $\quad$ Dielectric constant $=3.4$

- $\quad$ Frequency $(\mathrm{fr})=2.4 \mathrm{GHz}$.

- Height $(\mathrm{h})=1 / 16 \mathrm{Inch}=1.5 \mathrm{~mm}$.

- $\quad$ Velocity of light $(\mathrm{c})=3 \times 108 \mathrm{~ms}-1$.

- $\quad$ Practical width $\mathrm{W}=42.1 \mathrm{~mm}$.

- $\quad$ Loss Tangent $(\tan \delta)=0.001$

- $\quad$ Practical Length $(\mathrm{L}) \mathrm{L}=32.5 \mathrm{~mm}$.

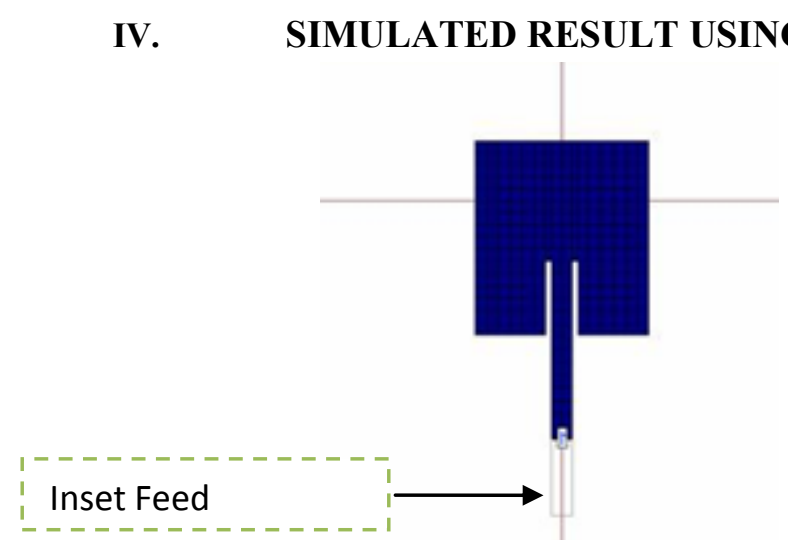

Fig. 2 Structural view of patch

From Fig. 3 it is concluded that the resonance frequency is $2.4 \mathrm{GHz}$, with the $\mathrm{dB}$ and Magnitude displayed v/s Frequency. This parameter describes the input-output relationship of an electrical system.

S-Parameters Display

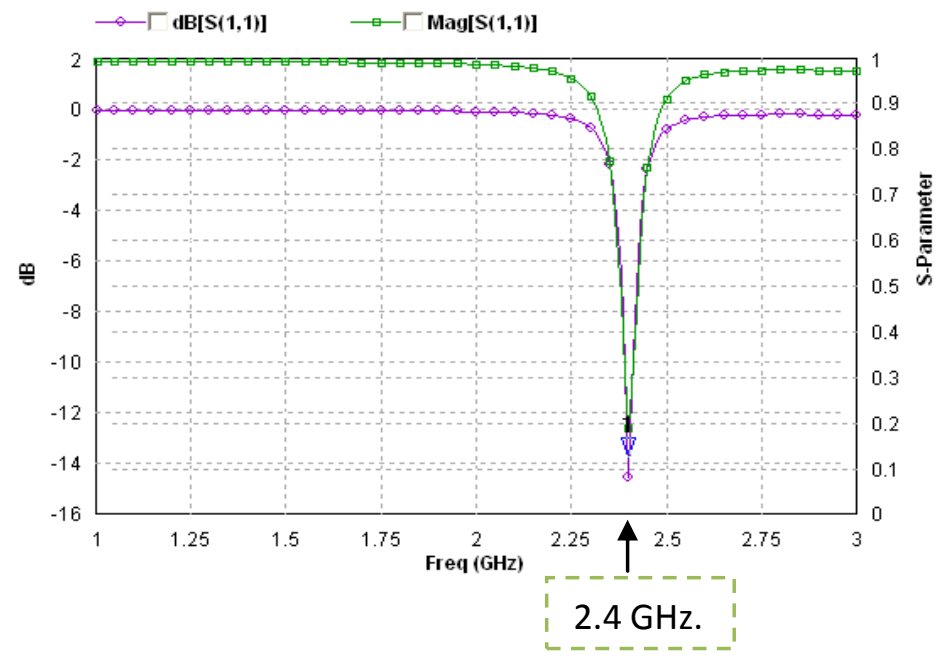

Figure 3. S Parameter Display 
The S parameter S11 depicts the Return Loss, with the resonant frequency at $2.4 \mathrm{GHz}$ and a return loss of about $-14 \mathrm{~dB}$ as shown from the figure. The S11 (Return Loss) parameter indicated the amount of power that is lost to the load and does not return as a reflection. This parameter was found to be of crucial importance to our project as we sought to adjust the antenna dimensions for a foxed operating frequency.

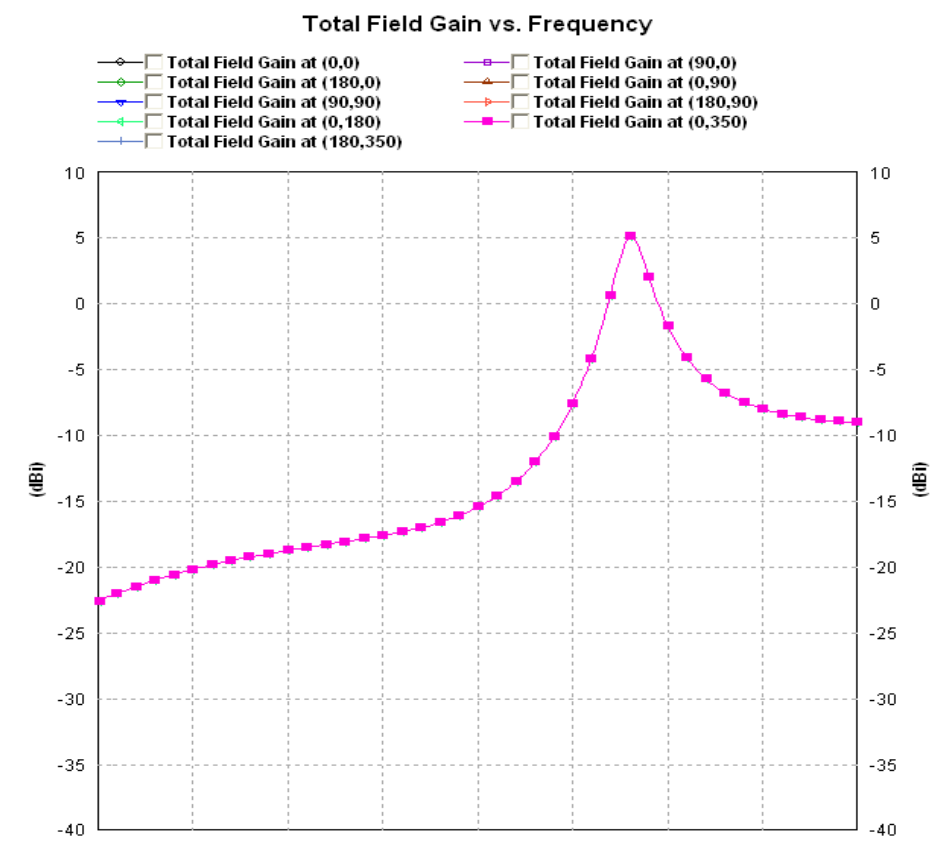

Figure 4. Field Gain vs. frequency plot
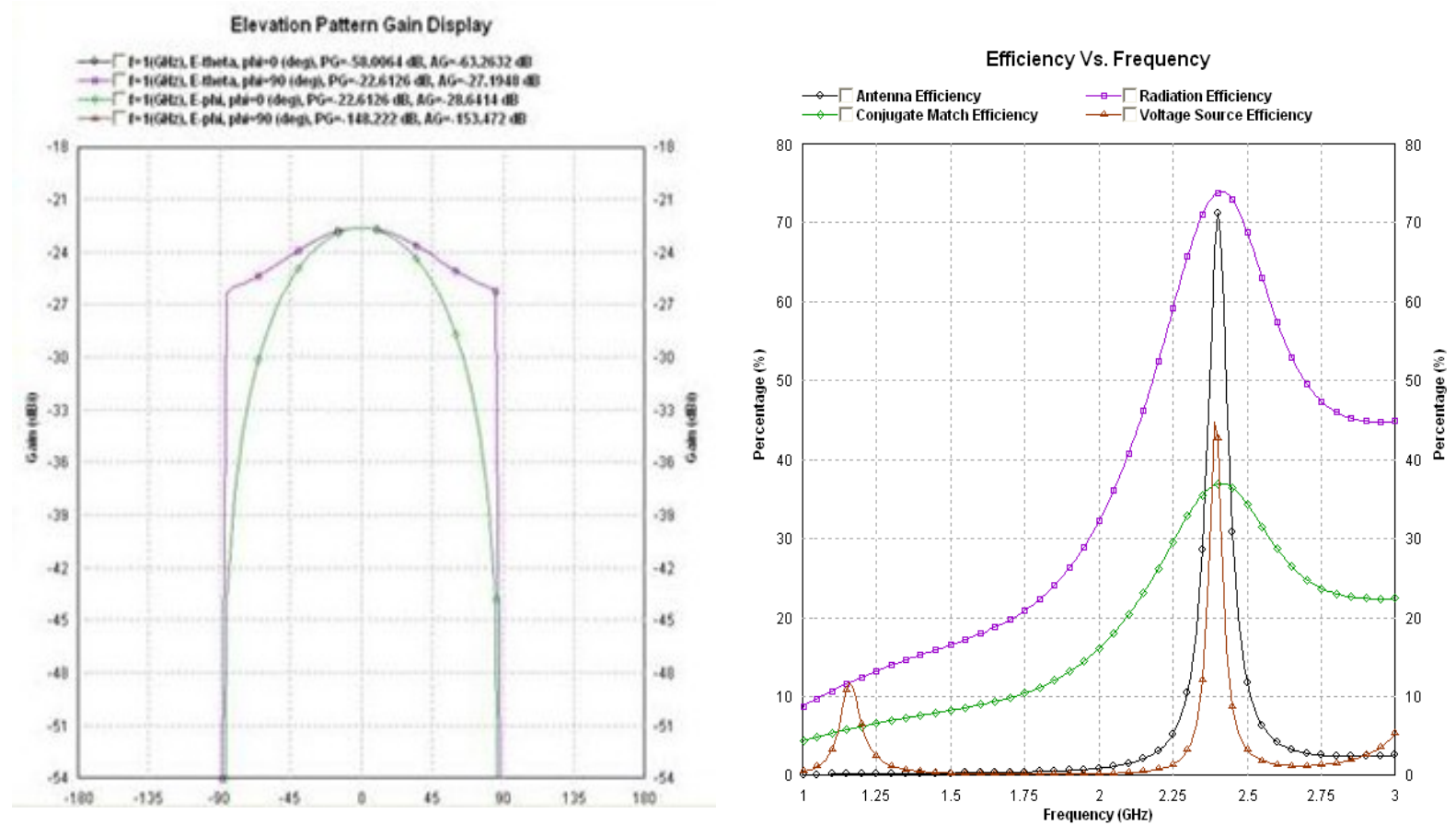

Fig.5.Elevation Pattern Gain Display at $\phi=-90$ to 90.

Fig.6. Efficiency v/s Frequency plot. 


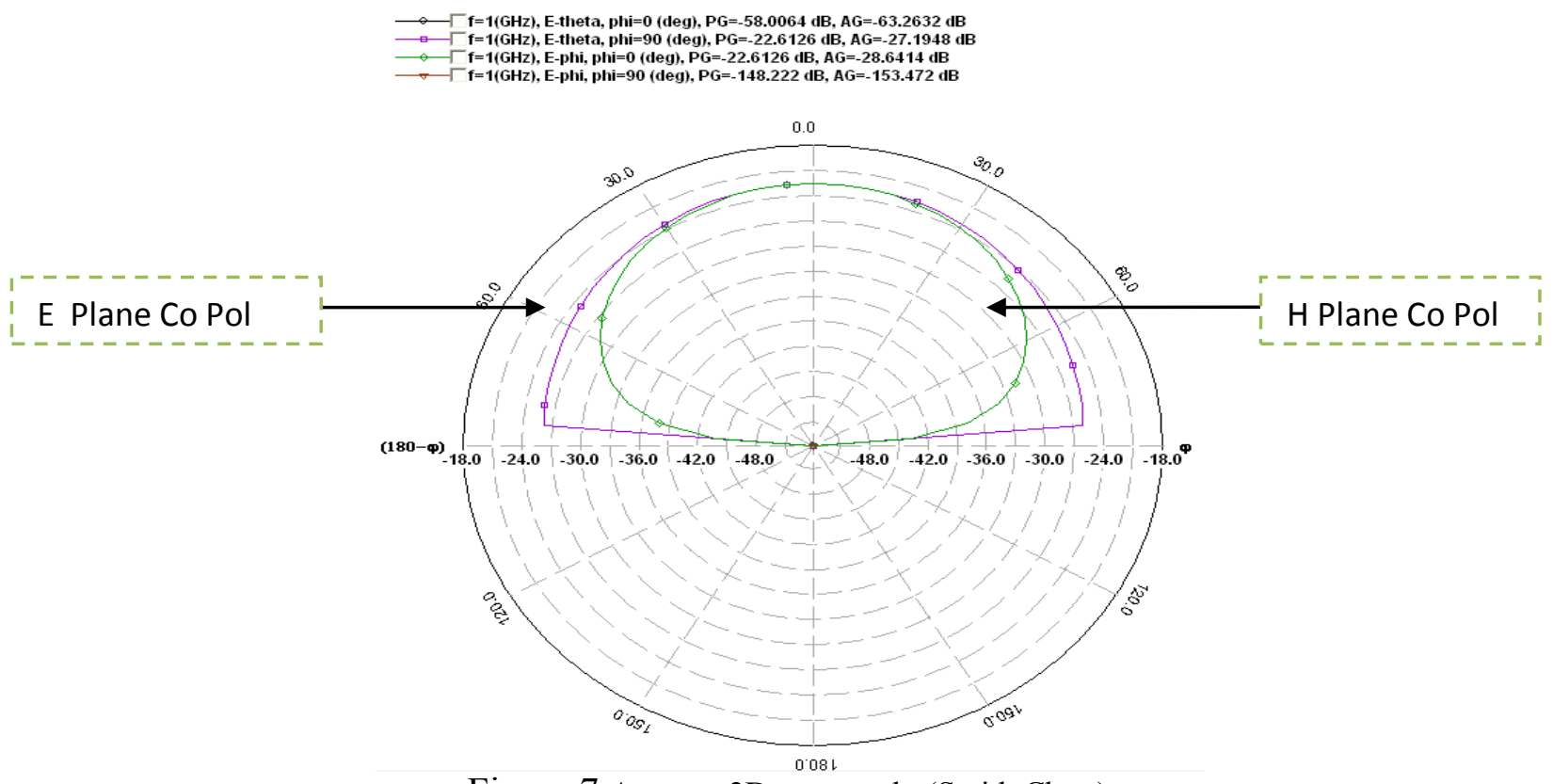

Figure 7.Antenna 2D pattern plot(Smith Chart)

\section{Radiation Pattern}

The patch's radiation at the fringing fields results in a far-field radiation pattern. This radiation pattern shows that the antenna radiates more power in a certain direction than another direction. The antenna thus possesses a certain directivity which is commonly expressed in dB's. The fringing fields at the radiating edges can be viewed as radiating slots above the ground plane. The rectangular patch excited in its fundamental mode has a moving away from broadside towards lower elevations.

\section{INDENTATIONS AND EQUATIONS}

The first paragraph under each heading or subheading should be flush left, and subsequent paragraphs should have a five-space indentation. A colon is inserted before an equation is presented, but there is no punctuation following the equation. All equations are numbered and referred to in the text solely by a number enclosed in a round bracket (i.e., (3) reads as "equation 3"). Ensure that any miscellaneous numbering system you use in your paper cannot be confused with a reference [4] or an equation (3) designation. (10)

\section{FIGURES AND TABLES}

To ensure a high-quality product, diagrams and lettering MUST be either computer-drafted or drawn using India ink.

Figure captions appear below the figure, are flush left, and are in lower case letters. When referring to a figure in the body of the text, the abbreviation "Fig." is used. Figures should be numbered in the order they

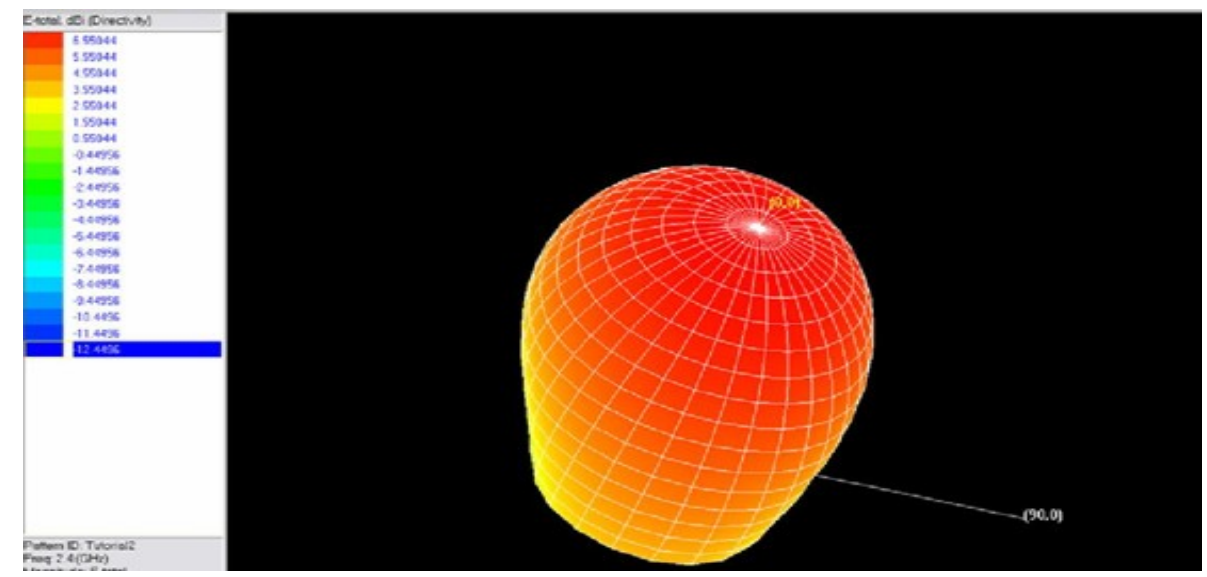

Fig.9. (a).3-D pattern of Axial ratio of antenna at frequency range $2.4 \mathrm{GHz}$ 


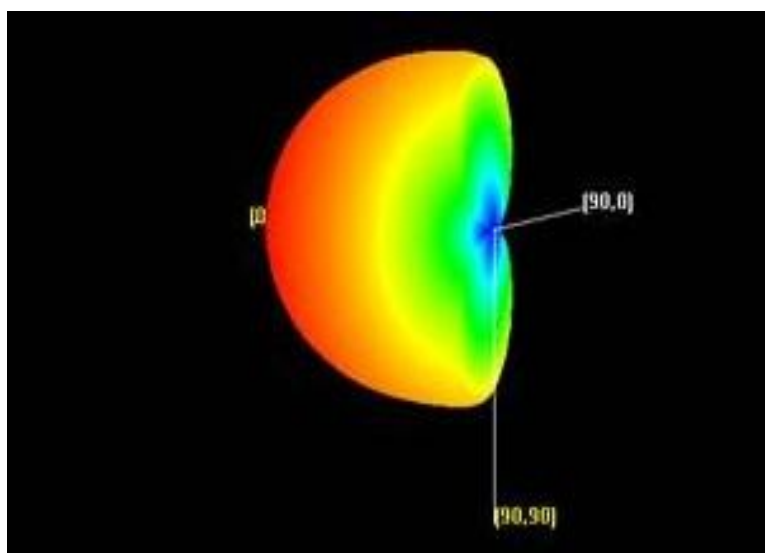

Figure.9. (b).Angular View

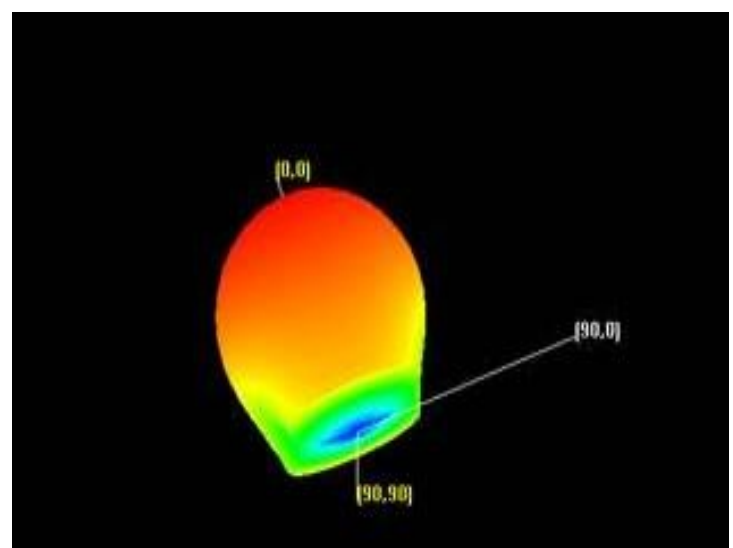

Figure.9. (c).Side View

\section{CONCLUSIONS}

In this work a novel Microstrip rectangular patch antenna at resonant frequency of $2.4 \mathrm{GHz}$ has been reported. The Radiation patterns (3D) and the other important parameters of gain, efficiency and return loss have been studied. The antenna's radiating elements are the main patch and the sub patches and it is possible to design the Microstrip patch antenna at any band of frequencies like L, S, C, X, Ku \& Ka bands. All parameters will be improved due to stacking of substrate, since effective dielectric constants get increased. The narrow beam gets rid off interference that permits reception-inside building where signals are too weak to be picked up by standard antenna. It delivers 10 times less radiations to user's head without any shielding device. It makes battery to last longer. The overall working of antennas was understood and the radiation patterns and gain v/s frequency plots were studied and their implications were understood.

\section{REFERENCES}

[1] Warren L Stutzman, Gary Thiele, Antenna Theory and Design, IEEE antenna definition.

[2] Antenna theory analysis \& design by C.A. Balanis, $2^{\text {nd }}$ Ed., John Wiley \& sons, inc. 2005, New York.

[3] Sunil Kr. Singh, S. K. Kundu, Ravi Prakash ,N. T Markad, "Microstrip Stacked Patch Antenna for next generation GSM", IJENGG, Volume 2, November 4, December 2009.

[4] H.Legay; L.Shafai, "New stacked microstrip antenna with large band width \& high gain".

[5] K.F.Lee, W.ehen and R.Q. Lee,"Advance in microstrip \& printed antennas", John Willey and sons, inc, 1997.

[6] Maha Abdelmoneim and Mohamed Ali "Design and Analysis of Adaptive and reconfigurable antenna for Wireless communication",

[7] Nonder Behdad "Simulation of patch Antenna"

[8] Robert E.Munson"Conformal microstrip antennas and microstrip phased Arrays”. IEEE Trans. Antenna and propagation, pp74-79, Jan 1974.

[9] Srin Das, Santosh K. Choudhary "Rectangular microstrip antenna of ferrite substrate" IEEE Trans Antenna and Propagation vol.AP-13, No.3 pp.499-502, May 1982.

[10] Svacina J."Analysis of multilayer microstrip lines by a conformal mapping method" IEEE Trans on microwave theory and Technique vol.40, No.11, Nov.1992 pp.2116.

[11] D. orban and W.K.M oernout "The basis of patch antenna".

[12] Wayne Tomasi, “Advance Electronics Communications Systems", $6^{\text {th }}$ Edition, Pearson Education, Kindersley, 2006.

[13] Behrouz A. Forouzan, "Data Communications and Networking", $4^{\text {th }}$ Edition, the McGraw-Hill Companies, New York, 2006.

[14] http://www.wikipedia.com.

[15] Thedore S. Rappaport, “WirelessCommunication”, $2^{\text {nd }}$ Edition, the Prentice-Hall ofIndia, New Delhi, 2007.

[16] Fremont: IE3D reference manual 10, Zealand Software. Inc; 2006, www.zealand.com

[17] Supriya Jaiswal1, HaneetRana2 ,PaurushBhulania, International Journal Of Advance Research In Science And Engineering, MICROSTRIP PATCH ANTENNA ARRAY

[18] Jhaman Das,International Journal of Engineering Science and Technology (IJEST)Rectangular Patch Antenna Array for Wireless Application. 